\title{
Clinical evaluation of clobetasone butyrate eye drops in the treatment of anterior uveitis and its effect on intraocular pressure
}

\author{
L. A. EILON AND S. R. WALKER* \\ From the Medical Division (Established Products), Glaxo Group Research Limited, \\ Greenford, Middlesex
}

SUMMARY Clobetasone butyrate has been formulated as a new steroid preparation for use in ophthalmology and has been compared with prednisolone phosphate and betamethasone phosphate in the treatment of anterior uveitis. The results from 4 double-blind, between-patient studies have shown that all 3 treatments are effective in reducing the signs and symptoms of this intraocular disease. $87 \%$ of those patients receiving clobetasone butyrate had a good or satisfactory response, but no differences in therapeutic efficacy were observed between these 3 steroid treatments. Clobetasone butyrate had little effect on intraocular pressure when compared with dexamethasone or hydrocortisone, both of which cause a significant rise in intraocular pressure.

A new steroid eye drop preparation containing clobetasone butyrate is undergoing clinical evaluation and has been reported to have an anti-inflammatory efficacy similar to betamethasone and prednisolone eye drops. ${ }^{12}$ In addition patients known to experience a rise in their intraocular pressure following the instillation of dexamethasone or betamethasone phosphate eye drops have been found to have a much lower response after clobetasone butyrate.

This paper describes 4 double-blind, betweenpatient clinical studies in which clobetasone butyrate eye drops were compared with either betamethasone phosphate or prednisolone phosphate eye drops in the treatment of anterior uveitis. In addition this steroid has been compared with dexamethasone and hydrocortisone for its effect on intraocular pressure.

\section{Patients and methods}

UVEITIS STUDIES

Patients who were diagnosed as suffering from acute anterior uveitis were selected for these studies. The nature and purpose of the studies were explained to the patients, after which they gave their consent to participate in the investigation. Each patient received one of the steroid preparations, i.e., clobetasone

${ }^{*}$ Present address; Centre for Medicines Research, 12 Whitehall, London.

Correspondence to Mrs Louise Eilon. butyrate $(0 \cdot 1 \%)$, betamethasone phosphate $(0 \cdot 1 \%)$, or prednisolone phosphate $(0.5 \%)$, by random allocation, and the studies were double-blind. The dosage prescribed was 2 drops instilled 2 hourly reducing to 2 drops 4 times a day at the discretion of the ophthalmologist. Patients received atropine drops if necessary or acetazolamide when indicated for secondary glaucoma. Ninety patients ( 31 females, 59 males) were studied. The number of patients and comparative products investigated in each of the four studies are given in Table 1. Forty-seven patients received clobetasone butyrate, 33 received betamethasone phosphate, and 10 patients received prednisolone phosphate.

Patients were assessed initially and at approximately weekly intervals for 3 or 4 weeks. In studies 1 and 2 the following signs and symptoms were scored on a 0 to 3 scale (where 0 is absent and 3 is severe): blurring, redness, watering, photophobia, pain, ciliary injection, corneal oedema, keratic precipitates, flare, cells, and exudate. The assessment of treatment was considered to be 'good' if the total score fell to between 0 and 2 within 3 to 4 weeks, 'satisfactory' if the score fell to between 3 and 7, and 'poor' if there was no reduction in score or patients were withdrawn because of a worsening of the disease. In study 3 only the signs of the disease were recorded as above, and in addition the clinician assessed the response as good, satisfactory, or poor after 3 weeks' treatment. In study 4 the response at each visit was assessed as 
Table 1 Details of patients in each clinical study

\begin{tabular}{|c|c|c|c|c|c|c|}
\hline \multicolumn{5}{|c|}{ Number of patients } & \multirow{2}{*}{$\begin{array}{l}\text { Age range. } \\
\text { years }\end{array}$} & \multirow[t]{2}{*}{ Total } \\
\hline Studv & $\begin{array}{l}\text { Clobetasone } \\
\text { butyrate }\end{array}$ & $\begin{array}{l}\text { Betamethasone } \\
\text { phosphate }\end{array}$ & $\begin{array}{l}\text { Prednisolone } \\
\text { phosphate }\end{array}$ & $\begin{array}{l}\text { Females and } \\
\text { males }\end{array}$ & & \\
\hline 1 & $12^{*}$ & 8 & - & $8 \mathrm{~F} .12 \mathrm{M}$ & $23-74$ & 20 \\
\hline 2 & 12 & 12 & - & $8 F .16 M$ & $15-80$ & 24 \\
\hline 3 & 11 & - & 10 & $7 F, 14 M$ & $20-79$ & 21 \\
\hline 4 & 12 & 13 & - & $8 F .17 \mathrm{M}$ & $29-73$ & 25 \\
\hline Total & 47 & 33 & 10 & $31 \mathrm{~F} .59 \mathrm{M}$ & $15-80$ & 90 \\
\hline
\end{tabular}

*One patient both eves treated.

excellent, good, satisfactory, or poor, but in the analysis of the results the assessments of good and excellent have been combined.

INTRAOCULAR PRESSURE STUDY

This was a within-patient open comparative study to investigate the effect on intraocular pressure of clobetasone butyrate $(0 \cdot 1 \%)$ and neomycin $(0.5 \%)$ eye drops with dexamethasone $(0 \cdot 1 \%)$ or hydrocortisone $(1.5 \%)$ and neomycin $(0.5 \%)$ (NeoCortef) in those patients who were either known to sustain a rise in their intraocular pressure following the instillation of dexamethasone or were suspected of being 'steroid responders'. In 4 female patients dexamethasone was administered to one eye only (1 drop 3 times a day) for a period of between 4 and 6 weeks. At a later date,

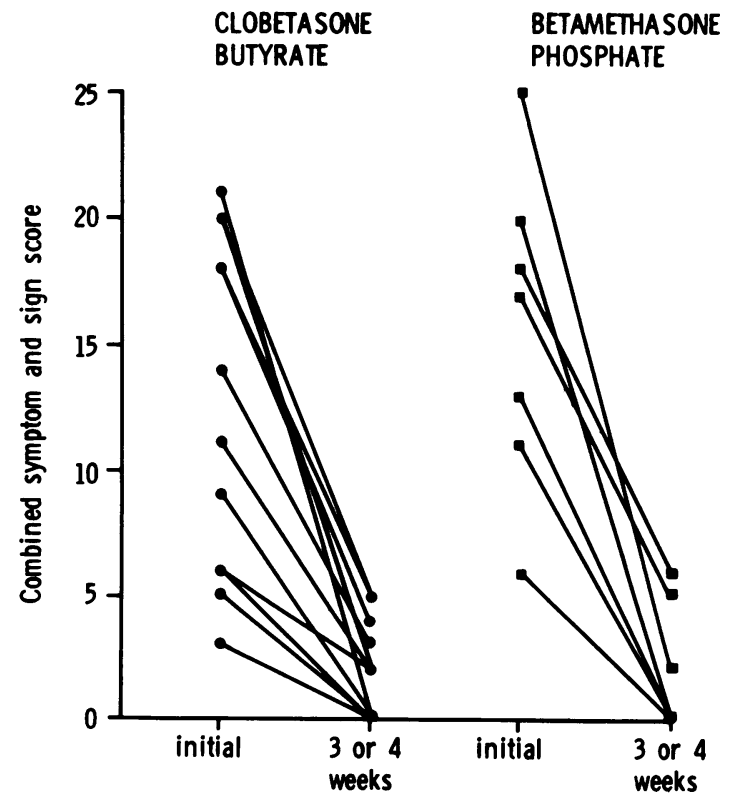

Fig. 1 Study 1. Change in symptom and sign score following treatment with clobetasone butyrate or betamethasone phosphate eye drops. after a period of no treatment the intraocular pressure having returned to normal, clobetasone butyrate with neomycin was instilled into one eye only (1 drop 4 times a day) for a period of 6 weeks. Intraocular pressure was measured at 2-weekly intervals over this period of time. In 2 female patients suspected of being 'steroid responders' hydrocortisone with neomycin was administered topically to one eye (1 drop 4 times a day) for a period of 4 weeks, the other eye receiving no treatment. After a period of one week's rest clobetasone butyrate with neomycin eye drops were instilled into one eye ( 1 drop 4 times a day) for a total period of either 4 or 6 weeks.

\section{Results}

\section{UVEITIS STUDIES}

Study 1 compared clobetasone butyrate in 12 patients with betamethasone phosphate eye drops in 8 patients. Fig. 1 shows the individual results and Table 2 summarises the patients' response to treatment. One patient received clobetasone butyrate in both eyes, and one in each group was withdrawn because of a worsening of the uveitis. The patient withdrawn from the betamethasone group also complained that the drops caused stinging on instillation. Twelve out of 13 eyes treated with clobetasone butyrate and 7 out of the 8 receiving betamethasone phosphate obtained a good or satisfactory response to treatment.

Study 2 compared clobetasone butyrate with betamethasone phosphate eye drops; 12 patients were

Table 2 Assessment of response

\begin{tabular}{llllll}
\hline Trial & Steroid & Good & Satisfactory & Poor & Total \\
\hline 1 & CB & 8 & 4 & 1 & 13 \\
& BP & 5 & 2 & 1 & 8 \\
2 & CB & 6 & 5 & 1 & 12 \\
& BP & 7 & 1 & 4 & 12 \\
3 & CB & 7 & 1 & 3 & 11 \\
& PP & 6 & 2 & 2 & 10 \\
4 & CB & 7 & 4 & 1 & 12 \\
& BP & 11 & 1 & 1 & 13
\end{tabular}

$\mathrm{CB}=$ clobetasone butyrate $(0 \cdot 1 \%) . \mathrm{BP}=$ betamethasone phosphate $(0 \cdot 1 \%)$. $\mathrm{PP}=$ prednisolone phosphate $(0.5 \%)$. 


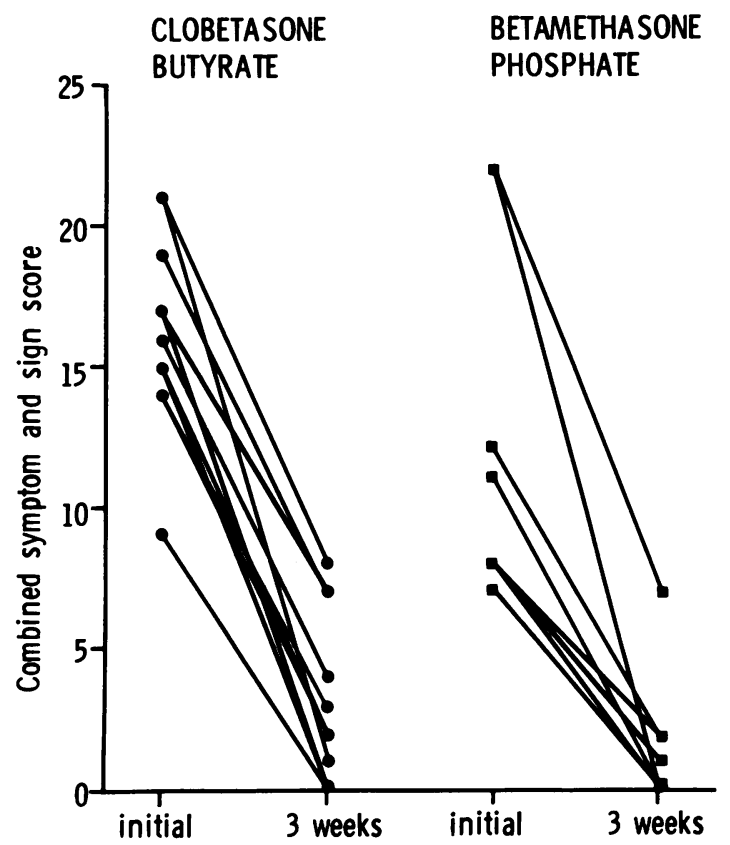

Fig. 2 Study 2. Change in symptom and sign score following treatment with clobetasone butyrate or betamethasone phosphate eye drops.

included in each group. Two patients in the clobetasone butyrate group failed to return to the clinic and one patient was withdrawn because there was no improvement. Both eyes of one patient were treated with betamethasone eye drops, but as there was no improvement in either eye the patient was withdrawn before the end of the trial. Two other patients in this group were withdrawn because of a worsening of the uveitis. The results after treatment are presented in Fig. 2 and summarised in Table 2. Four out of 12 patients receiving betamethasone phosphate had a poor response following treatment, whereas only one of the 12 patients receiving clobetasone butyrate had such a lack of response.

Study 3 compared clobetasone butyrate in 11 patients with prednisolone phosphate in 10 patients. Fig. 3 shows the individual results and Table 2 summarises the response to treatment. One patient in each treatment group was withdrawn because their uveitis deteriorated and another on each treatment showed no reduction in the sign score after 3 weeks' administration of the drops. However, 8 out of the 11 patients receiving clobetasone butyrate and 8 out of the 10 patients receiving prednisolone phosphate were considered to have a good or satisfactory response to treatment.

Study 4 compared clobetasone butyrate in 12

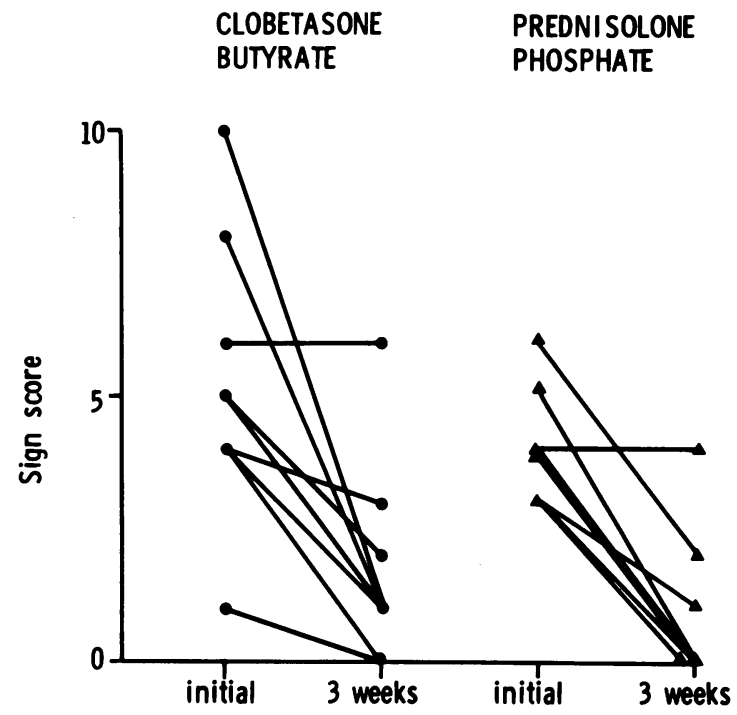

Fig. 3 Study 3. Change in sign score following treatment with clobetasone butyrate or prednisolone phosphate eye drops.

Table 3 Intraocular pressure measurements

\begin{tabular}{|c|c|c|c|c|c|c|}
\hline \multicolumn{2}{|c|}{ Patients } & \multirow[t]{2}{*}{ Steroid } & \multicolumn{2}{|c|}{ Intraocular pressure (IOP) } & \multirow{2}{*}{$\begin{array}{l}\text { Rise in } \\
I O P\end{array}$} & \multirow{2}{*}{$\begin{array}{l}\text { Length of } \\
\text { treatment (weeks) }\end{array}$} \\
\hline No. & Sex & & Initial & Final & & \\
\hline \multirow[t]{2}{*}{1} & $\mathbf{F}$ & Dexamethasone & 22 & 48 & 26 & 5 \\
\hline & & Clobetasone butyrate $(\mathrm{N})$ & 22 & 26 & 4 & 6 \\
\hline \multirow[t]{2}{*}{2} & $\mathbf{F}$ & Dexamethasone & 26 & 38 & 12 & 4 \\
\hline & & Clobetasone butyrate $(\mathrm{N})$ & 18 & 17 & -1 & 6 \\
\hline \multirow[t]{2}{*}{3} & $\mathbf{F}$ & Dexamethasone & 19 & 30 & 11 & 6 \\
\hline & & Clobetasone butyrate $(\mathrm{N})$ & 18 & 21 & 3 & 6 \\
\hline \multirow[t]{2}{*}{4} & $\mathbf{F}$ & Dexamethasone & 20 & 32 & 12 & 4 \\
\hline & & Clobetasone butyrate $(\mathrm{N})$ & 22 & 21 & -1 & 6 \\
\hline \multirow[t]{2}{*}{5} & $\mathbf{F}$ & Hydrocortisone (N) & 24 & 34 & 10 & 4 \\
\hline & & Clobetasone butyrate (N) & 20 & 19 & -1 & 4 \\
\hline \multirow[t]{2}{*}{6} & $\mathbf{F}$ & Hydrocortisone (N) & 18 & 29 & 11 & 4 \\
\hline & & Clobetasone butyrate $(\mathrm{N})$ & 20 & 19 & -1 & 6 \\
\hline
\end{tabular}


patients with betamethasone phosphate in 13 patients. The results given in Table 2 are the ophthalmologists' assessment after 3 to 4 weeks of treatment. Only one patient in each group had a poor response to the topical steroid treatment.

\section{INTRAOCULAR PRESSURE STUDY}

None of the 6 patients receiving clobetasone butyrate and neomycin eye drops experienced a significant rise in their intraocular pressure (i.e., greater than $6 \mathrm{mmHg}$ ) during the 6 weeks of the study (Table 3). However, rises of between 11 and $26 \mathrm{mmHg}$ were experienced by the 4 patients receiving dexamethasone over a similar period of time. Two patients receiving hydrocortisone and neomycin over a 4-week period had rises of 10 and $11 \mathrm{mmHg}$ respectively.

\section{Discussion}

From these clinical results it can be seen that clobetasone butyrate is effective in the treatment of anterior uveitis. In the 4 studies $87 \%$ of the patients treated with clobetasone butyrate had a good or satisfactory response after 3 weeks' treatment, and this was comparable to the $81 \%$ and the $80 \%$ of patients showing such a response after treatment with betamethasone phosphate and prednisolone phosphate respectively.

Dunne and Travers ${ }^{1}$ clearly showed the benefit of treating anterior uveitis with clobetasone butyrate or betamethasone eye drops compared with a placebo eye preparation. They did not, however, demonstrate a statistically significant difference in sign and symptom scores from patients receiving the steroid or placebo because of the limited number of patients studied. Although in many patients anterior uveitis is a self-limiting disease, steroids are of benefit in resolving the signs and symptoms quickly.

Previous studies have established that clobetasone butyrate has a minimal effect on intraocular pressure when compared with dexamethasone, ${ }^{1}$ betamethasone,$^{2}$ and prednisolone. ${ }^{3}$ The results of this investigation have confirmed the reduced propensity of clobetasone butyrate to raise intraocular pressure in known steroid responders when compared with dexamethasone and hydrocortisone. The significant intraocular pressure effect of hydrocortisone eye drops (with or without neomycin) has been confirmed by intraocular pressure and aqueous outflow measurements (Mapstone R, personal communication, 1980). In view of its reduced propensity to raise intraocular pressure, clobetasone butyrate would appear to be a useful new steroid preparation, having good anti-inflammatory activity and less effect on intraocular pressure than dexamethasone, betamethasone, prednisolone, and hydrocortisone.

The authors thank Mr M. J. Absolon, Southampton, Dr H. Gaston. Southampton, Mr A. J. Lyne, Peterborough, Mr H. E. Willshaw, Leeds, Mr R. P. Ellis, Plymouth, Mr J. L. Kennerley Bankes. London, Mr K. Jordan, Cambridge, Mr R. Mapstone, Liverpool. and $\mathrm{Mr} \mathrm{P}$. Drummond, Lincoln, for carrying out the investigations and for allowing their studies to be included in this paper.

\section{References}

1 Dunne JA, Travers JP. A double-blind clinical trial of topical steroids in anterior uveitis. Br J Ophthalmol 1979; 63: 762-7.

2 Ramsell TG. Bartholomew RS. Walker SR. Clinical evaluation of clobetasone butyrate: a comparative study of its effects on postoperative inflammation and on intraocular pressure. $\mathrm{Br} J$ Ophthalmol 1980; 64: 43-5.

3 Williamson J. Eilon LA. Walker SR. Clobetasone butyrate eye drops: effect on ocular inflammation and intraocular pressure. Trans Ophthalmol Soc $U K$ in press. 